\title{
IMPLEMENTASI STRUKTUR DATA TREE PADA GAME SNAKE DENGAN C
}

\author{
Dena Djayusman ${ }^{1}$, Ida Suhartini' ${ }^{2}$, Fadhlan Naufal Gunawan ${ }^{3}$, \\ Naufal Taufik Alhakim ${ }^{4}$, Thalissa Gunawan $\mathrm{A}^{5}$ \\ Politeknik Negeri Bandung \\ Jl. Gegerkalong Hilir, Ciwaruga, Kec. Parongpong, Kabupaten Bandung Barat, Jawa Barat 40559 \\ e-mail : dena.djayusman.tif19@polban.ac.id ${ }^{\mathbf{1}}$, ida@jtk.polban.ac.id², fadhlan.naufal.tif19@polban.ac.id ${ }^{\mathbf{3}}$, \\ naufal.taufik.tif19@polban.ac.id ${ }^{4}$, thalissa.gunawan.tif19@polban.ac.id ${ }^{5}$
}

\begin{abstract}
ABSTRAK
Permainan Snake merupakan sebuah permainan dengan konsep dimana pemain mengendalikan tubuh karakter permainan yang memanjang berupa sebuah garis. Tubuh dari karakter permainan tersebut dapat dijabarkan dengan struktur data tree. Struktur data tree digunakan untuk mengetahui keterkaitan antara bagian tubuh karakter yang satu dengan yang lainnya. Penerapan struktur data tree pada program terbagi dalam fungsi-fungsi yang merupakan dasar dari struktur program C. Dengan penerapan struktur data tree yang dibuat dalam program C, program permainan Snake ini dapat digunakan dan dikembangkan seperti program permainan Snake pada umumnya. Program ini dibuat dengan tujuan hiburan bagi pengguna-nya serta tujuan edukasi bagi tim pengembang, khususnya edukasi terkait ilmu struktur data tree.
\end{abstract}

Kata kunci: Program, Permainan Snake, Struktur Data Tree, Bahasa C

\begin{abstract}
Snake game is a game with a concept where the player controls the body of a game character that extends in the form of a line. The body of the game character can be described using a tree data structure. The data tree structure is used to determine the relationship between one character's body parts and another. The application of the tree data structure in the program is divided into functions which are the basis of the C program structure. With the application of the tree data structure created in the $C$ program, this Snake game program can be used and developed like the Snake game program in general. This program was created with the aim of entertainment for its users as well as educational purposes for the development team, especially education related to the science of data tree structures.
\end{abstract}

Keywords: Programs, Snake Games, Data Tree Structures, C Language

\section{PENDAHULUAN}

Permainan video merupakan permainan yang menggunakan interaksi dengan antarmuka pengguna melalui gambar yang dihasilkan oleh peranti video yang pada umumnya terdapat perhitungan tingkat keberhasilan yang dicapai dalam menyelesaikan setiap misi, biasa disebut dengan skor. Salah satu permainan video yang sering dijumpai yakni permainan Snake. Permainan Snake menuntut para pemain untuk teliti dan konsentrasi karena ketika memainkannya diharuskan untuk berusaha menghindar dari menabrak tubuh/obstacle dan mencari letak makanan yang dapat menambah panjang tubuh dari karakter tersebut.

Implementasi Struktur Data Tree Pada Game Snake Dengan C - (Dena Djayusman, Ida Suhartini, Fadhlan Naufal Gunawan, Naufal Taufik Alhakim, Thalissa Gunawan A) 
Dahulu permainan Snake berwarna hitam putih dengan visualisasi makanan berupa lingkaran hitam. Perkembangan antarmuka permainan video semakin meningkat seiring dengan berkembangnya teknologi dan teknik pengembangannya, sehingga saat ini permainan Snake dapat dijumpai dengan visualisasi karakter yang berwarna. Pada program C, terdapat beragam pilihan antarmuka. Untuk membuat program permainan, pilihan yang umumnya dipilih adalah console application dan console graphic application. Console application menampilkan visualisasi yang terkesan kaku, berbeda dengan aplikasi yang dibuat dengan pengaturan console graphic application.

Salah satu cara yang ditempuh agar antarmuka permainan Snake semakin menarik dalam visualisasinya adalah dengan memilih pengaturan program console graphic application dan menggunakan library graphics.h di mana library tersebut berisi tentang semua definisi dan penjelasan fungsi grafik. Dengan adanya ini maka dapat ditampilkan objek dalam mode grafik. Dengan begitu program permainan Snake yang dikembangkan akan lebih menarik minat serta lebih menghibur pengguna yang menggunakan program tersebut, sesuai dengan tujuan yang ingin dicapai. Konsep dasar dari program permainan yang akan dibuat berupa program permainan Snake dengan bahasa pemrograman $\mathrm{C}$ dan pemodelan struktur data tree, serta penggunaan file pustaka atau library graphics.

\section{KAJIAN PUSTAKA}

Konsep-konsep yang diterapkan pada pengerjaan program permainan Snake ini diantaranya yaitu,

\subsection{Struktur Data Tree}

Karakter dari permainan Snake dimodelkan menggunakan tree atau pohon. Struktur tree adalah struktur yang mengandung aspek hirarki yang dibentuk melalui pengelompokkan elemen atau node dalam tingkatan tertentu.

Terdapat macam-macam jenis tree beserta cabang ilmu lainnya yang berkaitan dengan jenis-jenis tree tersebut. Salah satunya adalah binary tree. Jenis tree tersebut identik dengan ciri parent yang pasti hanya memiliki dua anak.

\subsection{AVL Tree}

Guna meminimalisir kompleksitas waktu dalam proses pengolahan data pada tree yang diterapkan, maka diperlukan metode otomatisasi penyeimbangan tinggi pohon. Metode ini disebut AVL tree yang dimanfaatkan pada pohon biner (binary tree). Waktu yang dibutuhkan dalam pencarian data, dijamin bernilai konstan apabila metode ini diterapkan.

Penyeimbangan tinggi pohon dilakukan dengan proses rotasi. Proses rotasi tersebut menyebabkan adanya pergeseran pointer yang menunjuk root pada tree serta terbentuknya jalur node baru. Jalur node baru tersebut pastinya memiliki nilai seimbang ketika dihitung oleh otomatisasi AVL.

\subsection{Analisis}

Berdasarkan metode yang telah dipaparkan serta penggambaran program yang akan dikembangkan, analisis terhadap implementasi pun dilakukan. Struktur data tree beserta AVL tree hanya dapat diimplementasikan pada karakter permainan yaitu snake.

Karakter permainan snake digambarkan memiliki bentuk tubuh yang dapat terus memanjang dalam kondisi tertentu. Tubuh itu sendiri terbagi menjadi tiga bagian utama, yaitu kepala, badan, serta bagian tubuh belakang snake.

Masing-masing bagian tubuh karakter snake ditampung dalam node yang berbeda. Pada waktu terjadinya penambahan panjang tubuh karakter snake, maka jumlah node pada model tree akan turut bertambah jumlahnya.

Implementasi binary tree dirasa akan lebih efisien karena nantinya dapat diterapkan $A V L$ yang mempercepat proses pengolahan data pada tree. Sehingga program dapat bekerja secara lebih optimal, dijelaskan pada gambar dibawah ini. 

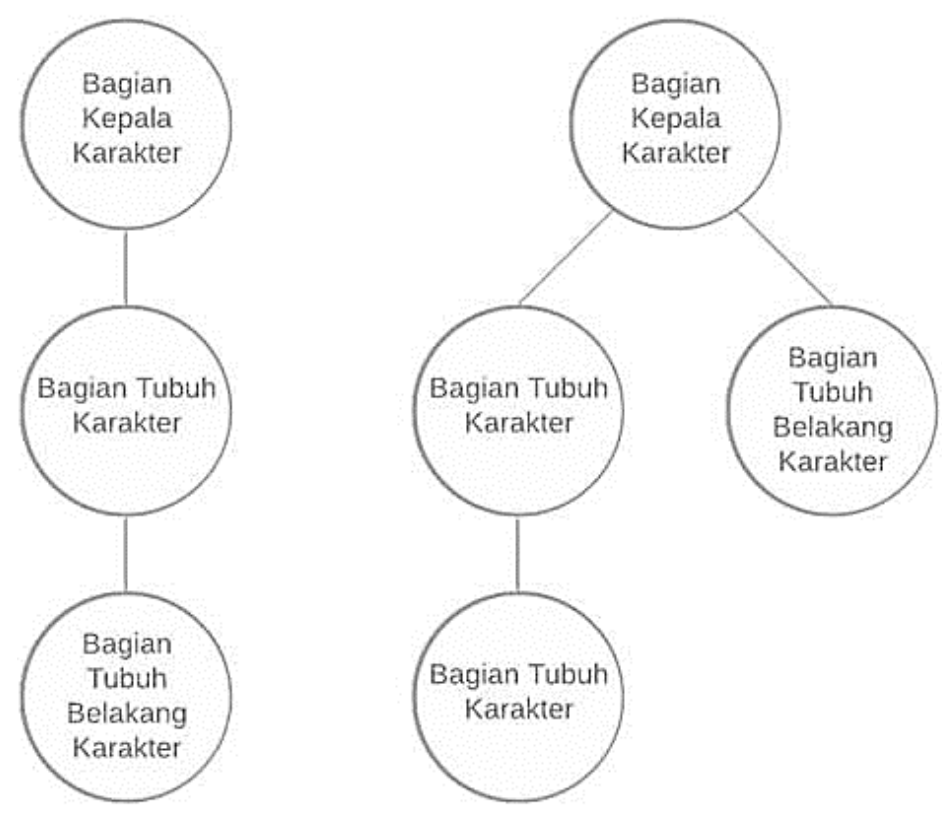

Gambar 1. Pemodelan karakter Snake menggunakan tree

\section{METODE PENELITIAN}

\subsection{Metode Perancangan}

Dalam pembuatan permainan Snake tentunya dibutuhkan sebuah tahapan perancangan agar permainan yang dibuat sesuai dengan yang diinginkan. Secara garis besar terbagi menjadi beberapa tahapan berikut :

1. Tahap Riset dan Penyusunan Konsep Dasar

Pada tahap ini konsep dasar, tema, teknologi, media (platform), serta berbagai batasan lain dirumuskan. Tahapan riset ini menjadi sebuah tahapan penting, berbagai elemen dasar dari permainan disusun di sini.

2. Perumusan Mekanika Permainan

Pada tahap ini tim pengembang merumuskan mekanika permainan. Mekanika permainan merupakan pola, aturan, atau mekanisme yang mengatur bagaimana proses interaksi pemain dengan permainan yang dibuat.

3. Penyusunan Asset dan Level Design

Tahapan ini fokus pada penyusunan konsep dari semua karakter serta asset termasuk suara/musik yang diperlukan. Pada tahap ini pula tim pengembang melakukan pengelompokan tingkat kesulitan serta berbagai asset yang tepat sehingga permainan dapat menghadirkan pengalaman bermain yang optimal.

4. Development

Pada tahap ini seluruh konsep yang sebelumnya telah tersusun mulai dikembangkan secara penuh serta semua elemen mulai dipadukan.

5. $\quad$ Testing

Pada tahap ini berfokus untuk mengetahui apakah semua komponen utama permainan mampu memberikan pengalaman bermain yang diharapkan serta dapat diketahui apakah ada masalah teknis yang belum terdeteksi sebelumnya. 


\subsection{Perancangan Modul}

Dalam pembuatan program, tentu saja diperlukan beberapa modul yang mana dalam modul-modul tersebut berisi logika yang menjadi dasar berjalannya program. Modul-modul utama yang akan diimplementasikan sebagai berikut :

1. Modul dengan fungsi umum yaitu menampilkan. Misalnya menampilkan arena permainan, papan jumlah perolehan skor dan nyawa karakter, menampilkan karakter snake, dan objek makanan karakter snake. Ciri umum dari modul dengan fungsi ini adalah kata "Display" pada awal penamaannya.

2. Modul dengan fungsi yang bersangkutan dengan logika dalam pemodelan karakter snake dengan struktur data tree. Modul ini nantinya terdiri atas modul InizializationSnake, AddSnake, CreateSnake, Height, BalanceFactor.

3. Modul dengan fungsi untuk mengatur gerakan karakter. Modul ini memiliki ciri umum pada penamaan modulnya, yaitu terdapat kata yang merujuk ke macam-macam arah, misalnya kanan $($ right) dan kiri (left).

\subsection{Perancangan Tampilan}

Antarmuka dari program menjadi salah satu unsur penting, guna menarik minat pengguna serta kenyamanan visual. Antarmuka yang menjadi output dari program permainan snake ini dirancang untuk menampilkan,

1. Karakter snake, terdiri dari kepala, tubuh, dan ekor,

2. Objek makanan karakter, terbagi menjadi makanan utama, makanan bonus, dan makanan jebakan,

3. Latar belakang/background,

4. Button, terdiri dari button play game, dan button exit,

5. Menu, terdiri dari menu utama, map menu, pause menu, menu tutorial dan game over menu, serta

6. Area permainan dengan dua pilihan map yang dirancang berbeda.

\section{HASIL DAN PEMBAHASAN}

4.1 Implementasi Modul

Modul-modul yang diimplementasikan pada pembuatan permainan Snake sebagai berikut :

Tabel 1. Pengimplementasian Modul Permainan Snake

\begin{tabular}{|l|l|l|}
\hline No & \multicolumn{1}{|c|}{ Nama Modul } & \multicolumn{1}{|c|}{ Deskripsi } \\
\hline 1. & MainMenu & $\begin{array}{l}\text { Modul ini berfungsi untuk menampilkan } \\
\text { background main menu }\end{array}$ \\
\hline 2. & Tutorial & $\begin{array}{l}\text { Modul ini bertujuan menampilkan jenis kontrol } \\
\text { beserta fungsinya yang dapat digunakan dalam } \\
\text { programpermainan }\end{array}$ \\
\hline 3. & MapMenu & $\begin{array}{l}\text { Menampilkan background berupa pilihan map yang } \\
\text { dapat dipilih user }\end{array}$ \\
\hline 4. & PlayGame & $\begin{array}{l}\text { Memulai permainan utama yaitu permainan } \\
\text { Snake }\end{array}$ \\
\hline 5. & DisplayMap & $\begin{array}{l}\text { Menampilkan background berupa arena permainan } \\
\text { berdasarkan map pilihan user }\end{array}$ \\
\hline 6. & DisplayScore & Modul untuk menampilkan papan score ke layar \\
\hline
\end{tabular}


JURNAL DIGIT Vol. 11, No.1 Mei 2021, pp.20 27

\begin{tabular}{|l|l|l|}
\hline 7. & DisplayLives & $\begin{array}{l}\text { Modul untuk menampilkan papan jumlah nyawa } \\
\text { pemain ke layar }\end{array}$ \\
\hline 8. & InitializationSnake & $\begin{array}{l}\text { Menginisiasikan agar terbentuk 3 buah node yang } \\
\text { terhubung pada tree yaitu untuk node head, body, } \\
\text { dan tail snake nantinya }\end{array}$ \\
\hline 9. & AddSnake & $\begin{array}{l}\text { Menambahkan node baru sesuai ketentuan Binary } \\
\text { Search Tree (BST) serta memperhatikan } \\
\text { keseimbangan treenya }\end{array}$ \\
\hline 10. & CreateSnake & $\begin{array}{l}\text { Mengalokasikan node baru serta menginisiasi semua } \\
\text { isi nodenya }\end{array}$ \\
\hline 11. & Height & Modul untuk mencari height atau jumlah dari \\
\hline
\end{tabular}

\subsection{Implementasi Alur Program}

Berdasarkan rancangan dan implementasi modul, berikut ini alur program permainan snake secara keseluruhan

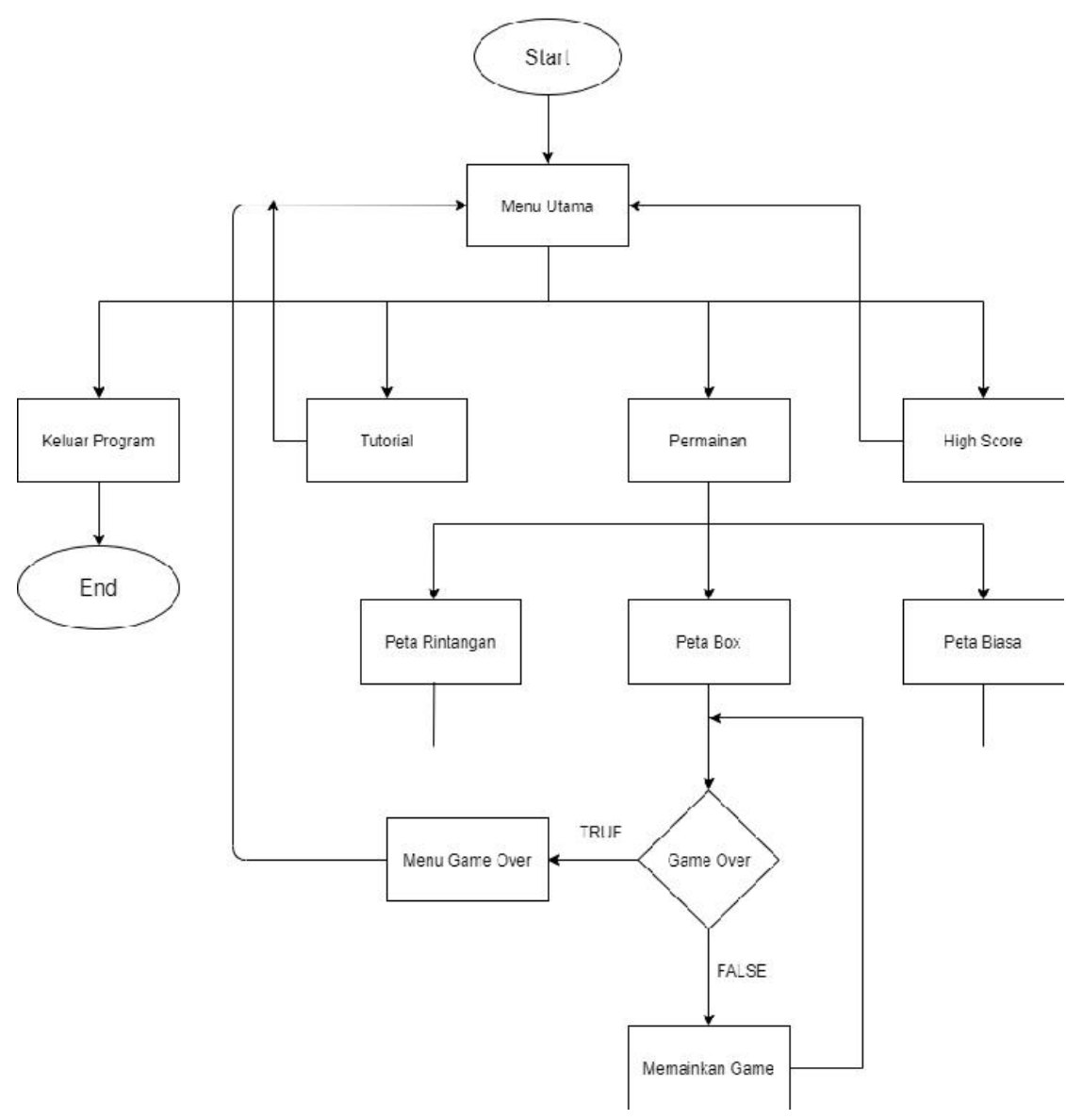

Gambar 2. Implementasi Alur program 


\subsection{Implementasi Tampilan}

Berdasarkan rancangan tampilan yang sebelumnya sudah dibuat, berikut ini hasil implementasi yang dibangun dengan memanfaatkan desain dengan lisensi yang mengijinkan pihak lain mempergunakannya untuk keperluan pribadi.

\subsubsection{Implementasi Bagian Tubuh Karakter Snake}
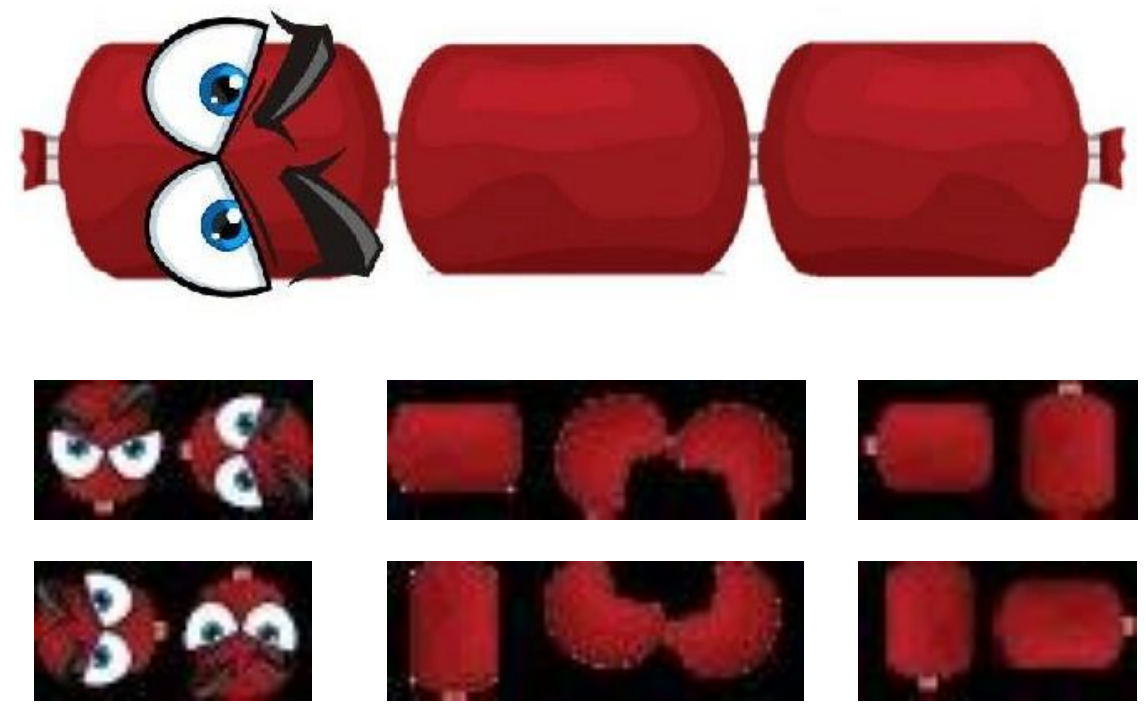

Gambar 3. Implementasi bagian tubuh karakter snake

Bagian tubuh karakter snake terdiri dari tiga bagian utama: kepala, tubuh, dan ekor. Bagian kepala dan ekor, masing-masing memiliki empat desain berbeda yang dibuat berdasarkan arah gerak karakter. Berbeda dengan bagian tubuh yang terurai menjadi enam bagian, empat diantaranya merupakan desain tubuh ketika karakter snake melaju dengan arah berbelok, sedangkan dua lainnya merupakan bentuk tubuh karakter ketika melaju secara normal baik vertikal maupun horizontal.

\subsubsection{Implementasi Objek Makanan Karakter}
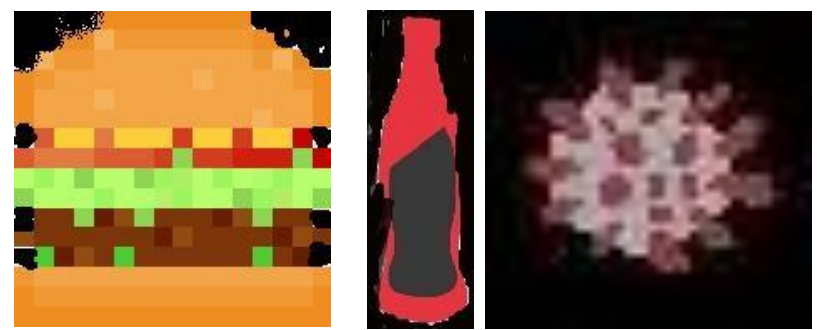

\section{Gambar 4. Implementasi objek makanan karakter snake}

Objek makanan merupakan salah satu objek penting selain karakter snake, karena objek ini lah yang menjadi arah tujuan gerak karakter snake sekaligus penentu skor yang akan dicapai oleh pemain. Tim pengembang membuat tiga jenis desain makanan: makanan utama, makanan bonus, dan makanan jebakan. Sesuai dengan nama-nya, ketiga makanan tersebut bisa menjadi keuntungan atau kerugian bagi pemain. 


\subsubsection{Implementasi desain latar belakang, button, menu, dan arena map}

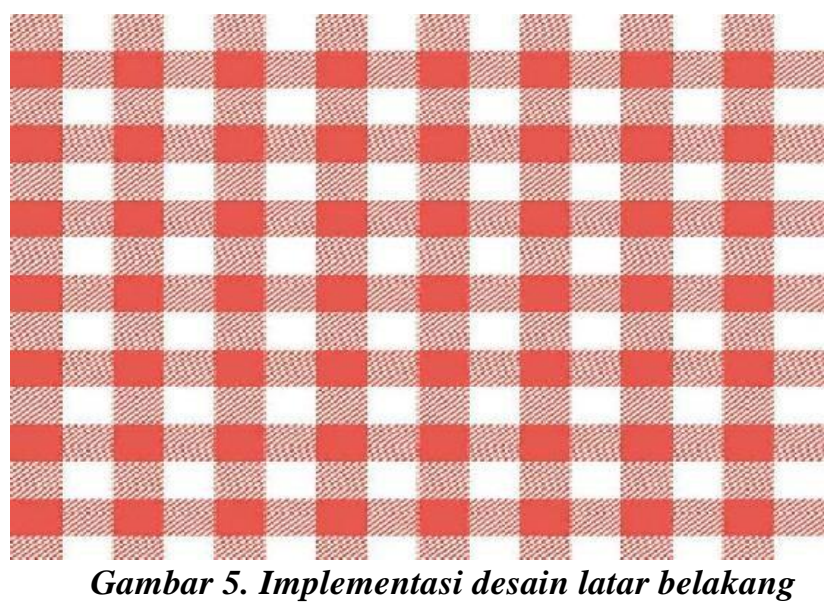

Desain latar belakang menjadi elemen yang cukup krusial dalam tahapan merancang antarmuka dari program. Objek atau komponen lainnya ditaruh di atas latar belakang tersebut, seperti karakter permainan, objek makanan, serta button yang dipergunakan untuk pengguna berinteraksi dengan menu-menu yang ada pada program.
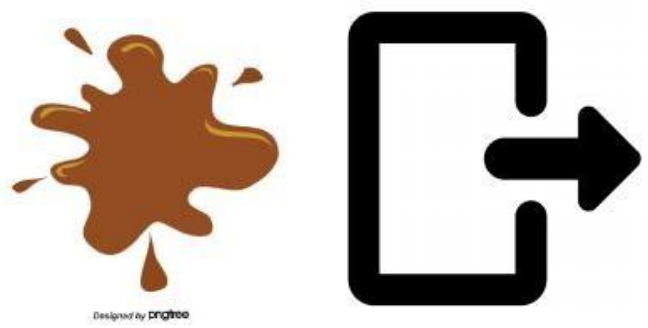

Gambar 6. Implementasi desain button
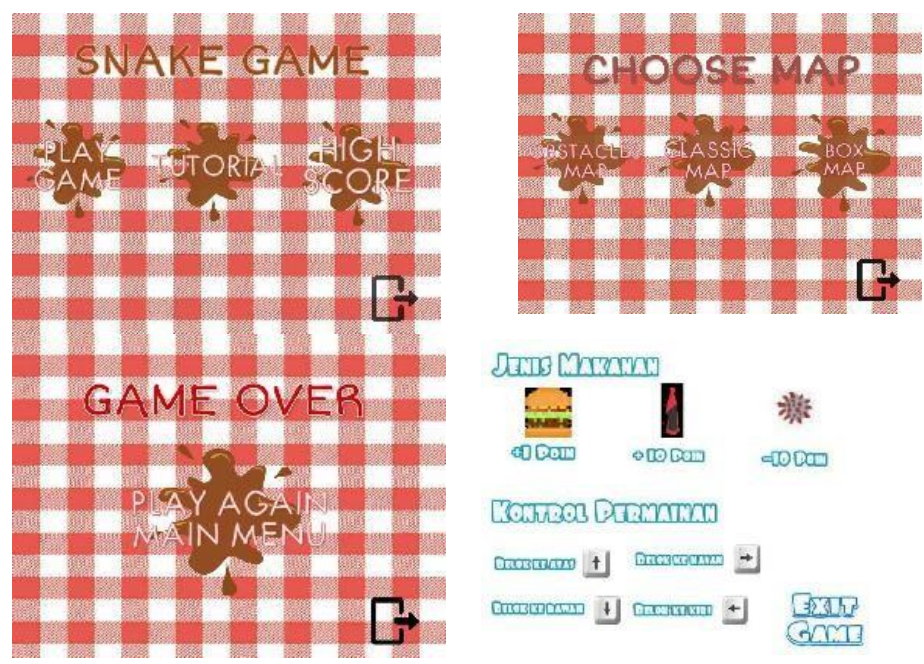

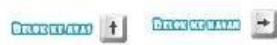

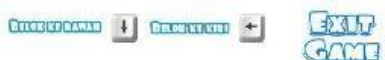

Gambar 7. Implementasi desain menu

Implementasi Struktur Data Tree Pada Game Snake Dengan C - (Dena Djayusman, Ida Suhartini, Fadhlan Naufal Gunawan, Naufal Taufik Alhakim, Thalissa Gunawan A) 


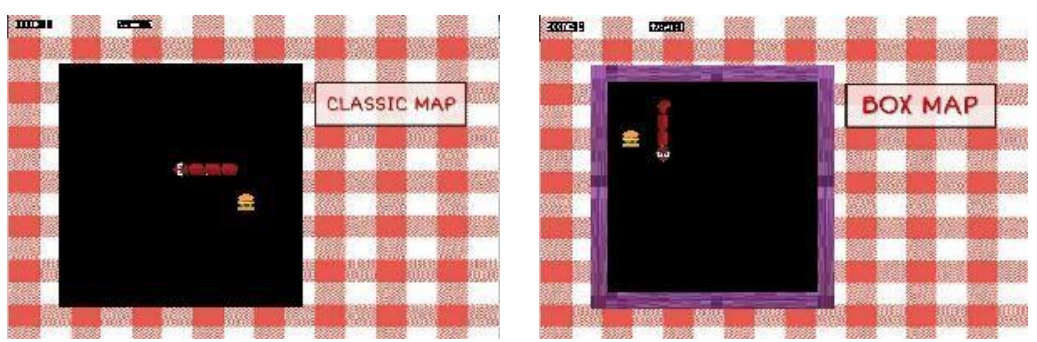

Gambar 8. Implementasi desain arena map

Arena map dibuat bervariasi untuk menambah tingkat kesulitan bagi pengguna yang memainkan program ini. Perbedaan dari kedua map yang diimplementasikan berada pada border yang terlihat mengelilingi arena permainan. Border tersebut di program dengan perulangan untuk ditampilkan pada arena.

\section{KESIMPULAN}

Kesimpulan yang dapat diambil dari analisis terhadap Implementasi Struktur Data Tree pada Game Snake dengan $\mathrm{C}$ adalah permainan snake dapat dimodelkan menjadi struktur data tree, juga dapat diterapkan ke dalam binary tree yang diotomatisasi dengan AVL. Pemodelan tree dilakukan terhadap bagian tubuh karakter snake pada permainan yang memiliki struktur utama yaitu kepala, tubuh, dan ekor. Dengan pemodelan tersebut, program dapat diproses dengan lebih optimal. Sehingga pengguna mendapatkan kemudahan dalam menggunakan program.

\section{DAFTAR PUSTAKA}

[1] M. W. Saputra, A. A. K. O. Sudana, dan I. M. Sukarsa, "Implementasi Struktur Data tree pada Sistem Informasi Upacara yadnya Berbasis Android”, MERPATI, vol. 2, no. 3, Des 2014.

[2] D. Wirdasari, "Membuat Program dengan Menggunakan Bahasa C", Jurnal SAINTIKOM, vol. 8, no. 1, Jan 2010.

[3] S. Suwanty dan O. Pribadi, "METODE AVL TREE UNTUK PENYEIMBANGAN TINGGI BINARY TREE”, JTM, vol. 4, no. 2, hlm. 61-65, Feb 2016. 